RESEARCH ARTICLE

\section{Examining High School Students' Personality Traits of Extraversion and Emotional Stability in Relation to their Academic Expectation and Value Appraisals}

\author{
Jonathan Smith ${ }^{1 *}$, Fanny-Alexandra Guimond ${ }^{2}$, Philip Aucoin ${ }^{2}$, Mathieu Gagnon ${ }^{1}$, \\ Daniel Moreau ${ }^{1}$, Jérôme St-Amand ${ }^{3}$, Jean-Philippe Ayotte-Beaudet ${ }^{1}$, and Etienne \\ Talbot $^{1}$ \\ 'Department of preschool and primary education, University of Sherbrooke, Canada \\ ${ }^{2}$ School of Psychology, University of Ottawa, Canada \\ ${ }^{3}$ Department of Educational Sciences, University of Quebec in Outaouais, Canada
}

Copyright: @2021 Smith, J. This is an open access article distributed under the terms of the Creative Commons Attribution License, which permits unrestricted use, distribution, and reproduction in any medium, provided the original author and source are credited.

\section{Corresponding author:} Jonathan Smith, U Department of preschool and primary education, University of Sherbrooke, Canada E-mail: jonathan.smith@usherbrooke.ca

\begin{abstract}
Both personality and motivational characteristics can be considered to estimate individuals' potential for adjustment and development. That said, these characteristics are rarely studied in conjunction. In this study, we examine how personality and motivational characteristics relate one to the other and influence how students approach learning. More precisely, we analyzed the additive and interactive effects of two intimately related traits (extraversion and emotional stability) from the Big Five model of personality on five motivational dimensions reflecting academic expectations (sense of competence) and values (interest, utility, and mastery and performance goal orientations). Data was collected from a sample of 303 students in tenth and eleventh grade (108 boys and 195 girls; Mage $=16.275$ years, $S D=1.149$ ) in a French-Canadian public high school in the greater Quebec City area. Primary analyses included both bivariate correlation and hierarchical regression analyses. Correlations indicated that emotionally stable students were more interested in learning. Hierarchical regression showed that emotionally stable students were more likely to exhibit a performance goal orientation, especially when they were extroverted. These analyses also revealed that emotionally stable students were more interested in learning, especially when they had a strong sense of competence. Results are discussed in light of the limited but relevant existing literature.
\end{abstract}

\section{Keywords}

Personality traits, extraversion, emotional stability, academic motivation, expectations for success, value of learning

\section{Introduction and Background}

Since the birth of psychology as a scientific discipline, researchers have strived to pinpoint "individual characteristics that would be quantitatively measurable" (Bernard, 2014) and that would help interpret how individuals adjust to, and even develop in different situations. To this end, many researchers have attempted to qualify this adjustment (to different situations) based on characteristics that are subject to variations over time and depending on contexts (e.g., feelings and emotions, beliefs, attitudes, and intentions; McAdams \& Pals, 2007; Nolen \& Ward, 2008). Such characteristics are known to influence individuals' behavior and, in fact, are considered to be fundamental motivational resources. On another hand, only a scarce proportion of these researchers have tried to make such estimations based on characteristics deemed relatively stable, such as temperament (Adamek et al., 2011; Schermerhorn et al., 2013; Séguin \& MacDonald, 2018) and personality traits (Kulig et al., 2019; Machimbarrena et al., 2019; Vreeke \& Muris, 2012). 
The work on feelings and emotions, beliefs, attitudes and intentions has attracted significant interest by providing insights for evaluating the motivational resources available to students and for implementing conditions and interventions that could help students acquire such resources. The research that has focused on temperament and personality traits, on the other hand, has garnered much less interest. Perhaps, as Bandura (2012) suggested, this is because such studies have focused on describing behavioural tendencies, but without considering the influence of contexts or situations that could exacerbate, neutralize or mitigate them.

Upon closer inspection, it does seem interesting to pay attention to certain personality traits, while attempting to evaluate individuals' motivational dispositions (or conditions that may exert an influence on such traits). More or less favourable characteristics of this type may facilitate or hinder the acquisition of certain motivational resources. At the very least, studies (De Pauw et al., 2009; De Young et al., 2010; Mervielde et al., 2005) that linked proand anti-social behaviors with different combinations of specific traits leave to think that there may be also associations between traits and motivational orientations (since motivation is known to exert an influence on behavior) (Schunk \& DiBenedetto, 2020). This hypothesis, in conjunction with such data, may have inspired researchers to try to link certain personality characteristics with motivational factors (Busato et al., 1999; Komarraju et al., 2009; Komarraju \& Karau, 2005; Matthews \& Zeidner, 2004; Phillips et al., 2003). The present study is driven by a similar aim, but more finely analyzes the links between certain personality traits and a structured set of dimensions that are known to play a fundamental role in the motivation to learn.

\section{An expectancy-value approach to motivation}

Motivation to learn is the central construct of the present study. It is known to be a complex, dynamic and multidimensional process. As a matter of fact, different theoretical approaches can be used to analyze the motivation to learn and most of them are based on a social cognitive paradigm. The current study relies on an expectancy-value approach which posits that students' interpretation of their likelihood of success regarding learning, and the value of learning, determine how they choose to behave, i.e., whether they engage and persist in order to achieve the learning in question (Schunk et al., 2008; Wigfield et al., 2016). A variant of this conceptualization, proposed by Pintrich and Schrauben (1992), allows not only to document the appraisal students make of their academic competence, as well as of the interest and the value of learning, but also their goal in relation to learning (e.g. masteryand performance- approach orientations), which are subject to match the aforementioned appraisals. These dimensions are considered in this study.

Sense of competence in itself can serve as a basis for inferring student expectations of success (Eccles et al., 1993; Eccles \& Wigfield, 1995). This sense reflects students' appraisal of their own skills in different areas of activity (Pinxten et al., 2014). Individuals' positive or negative appraisals are thought to depend on the quality of the experiences they have had over time, in relation to objects and situations associated with one of these activity areas (Bouffard \& Vezeau, 2015). Sense of competence could therefore have a significant bearing on interest in, importance assigned to, and goals related to learning (Smith et al., 2017; Usher \& Pajares, 2008), all of which are dimensions that help interpret the value students place on learning. Interest in learning refers to a short-lived or enduring psychological state that can be experienced by students when they engage in learning (Renninger \& Hidi, 2011). This interest is thought to have both an affective and a cognitive dimension. It may be accompanied with positive feelings, increased attention, and a willingness to take action to learn (Renninger \& Hidi, 2011). A related dimension, utility value of learning, refers to the personal meaning assigned to learning and the adoption of behaviors that should make it possible to carry it out (Wigfield et al., 2016). It seems important to note that perceived utility may depend on short-term or long-term goals (Wigfield et al., 2016). These goals may vary according to the situation (Putwain et al., 2013). Specifically, with respect to these goals, students may pursue mastery goals and thus demonstrate positive attitudes toward learning and focus on the acquisition of new knowledge and skills by mastering the tasks (Grant \& Dweck, 2003). Students might also pursue performance goals, in which case their major focus will be on demonstrating higher levels of knowledge and skills when compared and being recognized (Grant \& Dweck, 2003). 


\section{The "extraversion" and "emotional stability" traits of personality and their relationships with academic expectations and values}

The previous motivational dimensions help interpret whether students approach learning with confidence and enthusiasm. It may indeed be that, under the influence of personality traits, students develop a particular relationship to learning. At the very least, this is what is suggested by the notion that people with similar personality traits tend to act or react to situations in similar ways (Morizot \& Miranda, 2007). To this effect, different theoretical approaches have been proposed to measure personality traits. This study more specifically examines two closely related traits (David et al., 1997; Lu et al., 1997), extraversion and emotional stability, that stem from a broader five-trait approach (that allows also to assess openness to experience, agreeability and conscientiousness). These two traits are known to be reliable predictors of positive and negative affect (Lucas \& Fujita, 2000; Murray McNiel \& Fleeson, 2006) and very similar trends (at a precise time point or time intervals) have been found in numerous studies (McCrae et al., 2000). For these aforementioned reasons, this study only focuses on these two traits.

First, extraversion refers to a person's relationship with others and is more specifically used to describe the degree to which they are sociable, gregarious, open, and assertive (McCrae \& Costa, 2003). Individuals in whom this trait is dominant typically feel energized in situations where they are given an opportunity to interact with others. They also tend to be more likely to take risks and engage in thrill-seeking behaviours. Second, emotional stability refers to a person's tendency to preserve a stable emotional state (i.e., to remain calm and collected) in situations that cause worry or frustration (McCrae \& Costa, 2003).

A few studies have attempted to establish connections between such traits and characteristics that call to mind the motivational dimensions we have described. The primary goal in these studies is to predict and explain why students experience varying motivational processes as they approach learning. The findings emerging from these studies are as follows. Heaven (1990), in his research with Australian high school students, found that students who viewed themselves as extraverted were more motivated to learn. Two years later, Little, Lecci and Watkinson (1992) made a similar observation regarding the experiences of Canadian first-year university students. In this study, a link was drawn between students' personality traits and the content of their personal projects. Specifically, students who identified as extraverted more easily recognized the interest and importance of their various projects. That said, they preferred to devote themselves to projects involving social interaction over academic projects. Komarraju and colleagues $(2005,2009)$ made observations along similar lines in the context of two research projects in the United States. After observing that university students who were extraverted tended to display avoidancetype motivation, they noted that these same extraverted students were more likely to be dependent on external regulation than to be self-determined. This observation is almost identical to a finding uncovered one year earlier by Kaufman, Agars and Lopez-Wagner (2008) and one year later by Clark and Schroth (2010). These last two teams found that students at this level who described themselves as intrinsically motivated were also rather extraverted. Similarly, de Feyter and colleagues (2012) found that extraversion explains some of the variance in students' motivation to learn. These findings help to illustrate the influence that extraversion has on the different motivational dimensions considered in this study.

Similarly, there is research that allow us to evaluate the influence of emotional stability on these same dimensions. The results of a few studies suggest that students with positive emotionality are likely to exhibit greater motivation for learning. Conversely, it has been observed that learners who perceive themselves as being emotionally unstable may feel that they have limited control over situations (Little et al., 1992; Phillips et al., 2003). This perceived lack of control could concern them to the extent of taking over their thoughts and making it difficult for them to mobilize their personal resources effectively (Matthews \& Zeidner, 2004). That being said, it could be, as Norem and Cantor (1986) observed, that these concerns prompt such learners to step up their efforts, leading them to perform better than usual and, consequently, increasing their sense of competence. In addition, Little, Lecci and Watkinson (1992) observed that college students who displayed some emotional instability experienced less enjoyment in their interpersonal and academic undertakings. This finding is consistent with Watson and Hubbard's (1996) finding that highly emotionally unstable college students are more likely to give up on their goals when under stress. 
Busato, Prins, Elshout and Hamaker (1999), echoed and corroborated by Komarraju and Karau (2005), similarly suggest that emotional instability is detrimental to motivation, as it leads to the adoption of avoidance behaviors in learning situations.

\section{The present study}

For decades, researchers have been trying to identify factors that accurately assess students' degrees of confidence and enthusiasm toward school activities in general or certain tasks more specifically. As we have mentioned, the research carried out in the field of motivation has made an especially valuable contribution in this regard. These studies have shown, among other things, that certain feelings, emotions, beliefs, attitudes, and intentions can shape how students respond to learning opportunities (Atkinson, 1957; Eccles-Parsons et al., 1983; Elliot et al., 2011; Pekrun, 1993; Pintrich \& Schrauben, 1992; Rheinberg et al., 2000). These individual resources are known to be permeable and subject to change in relation to various factors, which is reassuring. Indeed, this means interventions can be carried out to help students acquire a set of resources that lead them to welcome new learning opportunities. There are, however, individual characteristics that cannot be influenced. Yet this does not make such characteristics any less interesting.

They remind us that certain interventions aiming to help students develop their motivational resources may require adjustments. To this end, psychology and education research often focuses on the adjustments that may be required by characteristics such as age (Ambady et al., 2001; Dotterer et al., 2009; Gottfried et al., 2009; Martin, 2009), sex (Fredricks \& Eccles, 2002; Frenzel et al., 2010) or race and ethnicity (Cohen et al., 1999; McKown \& Weinstein, 2008; Yeager et al., 2014). Characteristics, such as personality traits, receive much less attention. Yet, previously reported findings suggest that such characteristics may interact with motivation. These same findings, it must be acknowledged, have certain limitations. They allow only an approximate interpretation of the influence that different personality traits may have on characteristics that may be associated with motivational dimensions, since most of them are drawn from simple bivariate correlation analyses alone. If one were to attempt to interpret the characteristics of youths at the end of high school on the basis of such results, considerable caution would be required, as these results would be derived from data collected from adults rather than from high school-age youths (McCrae \& Costa, 2006).

In light of the above, this study will fill a gap in the literature by conducting an analysis of more subtle links that may exist between certain personality traits and motivational dimensions documented in students at the end of their high school careers. More specifically, this study has two objectives:

1- To identify the unique and interactive effects of extraversion traits and emotional stability on dimensions that are revealing of value placed on learning (interest in learning, utility value of learning, mastery goals, and performance goals); and

2- To examine the moderating effects of expectations of success (sense of competence) and gender in previous associations.

\section{Method}

\section{Participants and procedure}

This study used a convenient sample of 303 adolescents (108 boys, 195 girls) from a high school in the greater Quebec City area in Canada. Of this total sample, 168 were $10^{\text {th }}$ graders $\left(M_{\text {age }}=15.927\right.$ years, $\left.S D=.500\right)$ and $135,11^{\text {th }}$ graders $\left(M_{\text {age }}=16.700\right.$ years, $S D=$ 1.521). During January 2020 , a trained research assistant administered the questionnaire during regular class time. Students were instructed to keep their answers confidential and it took less than 40 minutes for them to complete the questionnaire. As for the questionnaire itself, it comprised 90 items in French that measured the five dimensions of the students' motivation and two personality traits, as well as dimensions of students' psychosocial adjustment. In order to answer the two objectives of this study, only the answers to the motivational and personality measures were used for analyses.

\section{Measures}

Sense of competence: Participants responded to this 4-item subscale that assessed their appreciation of their school competence (adapted from the work of Ntamakiliro, Monnard, \& Gurtner, 2000). Items ("I am proud of my grades at school", "I'm as good as others at school", "I am not very good at school", and "I'm not as good as others at school") were rated on a 
scale ranging from 1 (strongly disagree) to 6 (strongly agree). The last two items were reverse coded and item scores were averaged to generate a score reflecting a sense of competence $(M=4.410, S D=1.036, \alpha=.85)$.

Interest in learning: Participants responded to this 4-item subscale that assessed their interest in learning (Ntamakiliro, Monnard, \& Gurtner, 2000). Item ("I'm interested in what we learn at school", "I like going to school", "What we do in class is interesting", and "I'm often bored in class") were rated on a scale ranging from 1 (strongly disagree) to 6 (strongly agree). The last item was reverse coded and item scores were averaged to generate a score reflecting interest in learning $(M=3.290, S D=1.000, \alpha=.82)$.

Utility value of learning: Participants responded to this 4-item subscale that assessed the degree to which they think school has utility value (Ntamakiliro, Monnard, \& Gurtner, 2000). Items ("What we learn in school will be useful in life", "What we learn in school will be helpful in the future", "What we learn in school is useful", and "What we learn in school is not useful") were rated on a scale ranging from 1 (strongly disagree) to 6 (strongly agree). The last item was reverse coded and item scores were averaged to generate a score reflecting utility value of learning $(M=3.733, S D=1.029, \alpha=.87)$.

Mastery goal orientation: Participants responded to this 3-item subscale that assessed their mastery goals at school (Bouffard et al., 1998). Items ("It's important for me to understand what we're learning at school", "Understanding as much as possible is the most important thing for me at school", and "I want to learn as much as possible at school") were rated on a scale ranging from 1 (strongly disagree) to 6 (strongly agree). Item scores were averaged to generate a score reflecting mastery goal orientation $(M=4.220, S D=1.019, \alpha=.81)$.

Performance goal orientation: Participants responded to this 4-item subscale that assessed their performance goals at school (Bouffard et al., 1998). Items ("My main goal in school is to be the best", "It's important to me to be one of the best in my class", "My main goal in school is to get good grades", and "It's important to me to be better than other students") were rated on a scale ranging from 1 (strongly disagree) to 6 (strongly agree). Item scores were averaged to generate a score reflecting performance goal orientation $(M=$ 3.091, $S D=1.172, \alpha=.86)$.

Extraversion: Participants responded to this 10-item subscale of the Big Five Personality Trait Short Questionnaire (Morizot, 2014) that assessed their tendency to extraversion. An introductory phrase, "I see myself as someone who," preceded ten statements ("Likes to talk and express their opinions", "Is reserved or timid, and has difficulty reaching out to others", "Is full of energy and likes to always be active", "Is a leader capable of convincing others", "Is rather calm and doesn't talk much", "Shows confidence and is able to assert himself/herself", "Is timid and shy", "Is extraverted and sociable", "Likes exciting activities that provide thrills" and "Tends to laugh and have fun easily". Each statement was rated on a scale from 1 (strongly disagree) to 5 (strongly agree). Item scores were coded as a higher score means higher levels of extraversion and were averaged to generate a score reflecting this particular trait $(M=3.563, S D=.681, \alpha=.75)$.

Emotional stability: Participants responded to this 10-item subscale of the Big Five Personality Trait Short Questionnaire (Morizot, 2014) that assessed their tendency to be emotionally stable. An introductory phrase, "I see myself as someone who," preceded ten statements ("Tends to get depressed and sad easily", "Is generally relaxed and handles stress well", "Can be tense and stressed", "Worries a lot about many things", "Is emotionally stable and not easily upset", "Can be moody", "Remains calm in tense or stressful situations", "Can easily become nervous", "Tends to feel inferior to others", "Tends to be easily irritated". Each statement was rated on a scale from 1 (strongly disagree) to 5 (strongly agree). Item scores were coded as a higher score means higher levels of emotional stability and were averaged to generate a score reflecting this particular trait $(M=2.986, S D=.844, \alpha=.85)$.

\section{Plan of Analyses}

All analyses were performed using the Statistical Package for the Social Sciences (SPSS) v.26 software (IBM Corporation, 2019). Of the 308 participants, five had incomplete data and were therefore removed from our analyses, resulting in a final sample of 303 participants. As preliminary analyses, bivariate correlations were run among the study variables as well as independent t-tests to assess gender differences. Then, our main analyses consisted of two separate sets of hierarchical regression analyses. Each set had four identical models 
predicting each of the four achievement motivation dependent variables: interest in learning, utility value of learning, performance goal orientation, and mastery goal orientation.

In the first set of analyses, the first step of each of the four models included the independent variable (extraversion) and the potential moderators (emotional stability and gender) as predictors of the dependent variables examined separately (interest, utility value, performance goal orientation, or mastery goal orientation). In order to test whether emotional stability and/or gender could moderate the associations between extraversion and each of the dependent variables, two-way interaction terms (i.e., "extraversion * emotional stability" and "extraversion * gender") were added to the second and the third steps of each model. In the final step of each model, the three-way interaction term "emotional stability * sense of competence * gender" was tested to examine if the previous associations could differ for boys and girls.

In the second set of analyses, the first step of each of the four models included the independent variable (emotional stability) and the potential moderators (sense of competence and gender) as predictors of the dependent variables examined separately (interest, utility value, performance goal orientation, or mastery goal orientation).In order to test whether sense of competence and/or gender could moderate the relationship between emotional stability and each of the four dependent variables, two-way interaction terms (i.e., "emotional stability * sense of competence" and "emotional stability * gender") were added in the second and the third steps of each model. In the final step of each model, the three-way interaction term "emotional stability * sense of competence * gender" was tested to examine if the previous associations could differ for boys and girls.

All variables were z-standardized before performing the analyses and creating the interaction terms, with the exception of gender. When an interaction term was significant, Holmbeck's procedure (2002) was used in order to illustrate the interaction effect when the independent variable was high (i.e., $1 S D$ above the mean) and when it was low (i.e., $1 S D$ below the mean).

\section{Results}

\section{Preliminary analysis}

Table 1 depicted bivariate correlations between study variables. Emotional stability was positively associated with extraversion $(r=.333, p<.01)$ and interest in learning $(r=.143, p$ $<.01)$. Sense of competence was positively correlated with all of the achievement motivation outcome variables, which includes performance goal orientation $(r=.322, p<.01)$, mastery goal orientation $(r=265, p<.01)$, interest in learning $(r=.376, p<.01)$, and utility value of learning $(r=.195, p<.01)$. Lastly, all four of the outcome variables were positively correlated with one another ( $r$ 's $>.142$, $p$ 's <.05). Independent t-tests revealed gender differences on only one study variable: emotional stability, $t(300)=8.29, p<.001$. Boys $(M=.63, S D=.87)$ reported more emotional stability than girls $(M=-.26, S D=.91)$.

\section{Main analyses}

In the first set of analyses, the main effects and the interactions terms were not significant in predicting interest in learning, utility value of learning, and mastery goal orientation (results are not shown for parsimony). The model predicting performance goal orientation did, however, yield significant findings. As can be seen in Table 2, in the first step of the model, the independent variable (extraversion) and the moderators (emotional stability and gender) were not significant predictors of performance goal orientation. However, the two-way interaction term "extraversion * emotional stability" was a significant predictor of performance goal orientation $(b=.241, S E=.056, p<.01)$. To illustrate this interaction, we examined the association between extraversion and performance goal orientation in two cases: when students' level of emotional stability was high (1SD above the mean) and when it was low (1 $S D$ below the mean). As shown in Figure 1, the association between extraversion and performance goal orientation was only significant when students' emotional stability levels were high $(b=.215, S E=.082, p<.01)$. When students' emotional stability levels were low, the association between extraversion and performance goal orientation was no longer significant $(b=-.117, S E=.084, p=.154)$. Therefore, extroverted students had greater performance goal orientation but only when they also displayed high levels of emotional stability. When they had low levels of emotional stability, extraversion was not associated 
with their performance goal orientation. The two-way and three-way interaction terms including gender were not significant predictors of performance goal orientation. Hence, boys and girls did not differ regarding the patterns of results.

In the second set of analyses, the main effects and the interaction terms were not significant in predicting utility value of learning, performance goal orientation and mastery goal orientation (results are not shown for parsimony). The model predicting interest in learning did, however, yield significant findings. As can be seen in Table 3, emotional stability and sense of competence were both significant predictors of interest in learning $(b=.153, S E$ $=.059, p<.05$, and $b=.355, S E=.055, p<.001$, respectively), though gender was not. The two-way interaction term "emotional stability * sense of competence" was also a significant predictor of interest in learning $(b=.211, S E=.055, p=.01)$. To illustrate this interaction, we examined the association between emotional stability and interest in learning in two cases, when students' sense of competence was high (1 $S D$ above the mean) and when it was low (1 $S D$ below the mean). As Figure 2 shows, the association between emotional stability and interest in learning was significant but only when students' sense of competence was high ( $b$ $=.333, S E=.094, p<.01)$. When sense of competence was low, the association between emotional stability and interest in learning was not significant $(b=.026, S E=.076, p=.730)$. Therefore, emotionally stable students were more likely to be interested in their studies when they also had a good sense of competence. When they felt they were not competent, their emotional stability was not a predictor of their interest in learning. The two-way and threeway interaction terms including gender were not significant predictors of interest in learning. Hence, boys and girls did not differ regarding the pattern of results.

Table 1. Bivariate correlations $[95 \% \mathrm{Cl}]$ among study variables.

\begin{tabular}{|c|c|c|c|c|c|c|c|}
\hline & 1 & 2 & 3 & 4 & 5 & 6 & 7 \\
\hline & & $.333^{* *}$ & .039 & .041 & .018 & .036 & .043 \\
\hline 1. Extraversion & - & $\begin{array}{l}{[.221,} \\
.436]\end{array}$ & $\begin{array}{c}{[-.078} \\
.148]\end{array}$ & $\begin{array}{c}{[-.061,} \\
.143]\end{array}$ & $\begin{array}{c}{[-.097} \\
.131]\end{array}$ & $\begin{array}{c}{[-.081,} \\
.153]\end{array}$ & $\begin{array}{c}{[-.074,} \\
.170]\end{array}$ \\
\hline $\begin{array}{l}\text { 2. Emotional } \\
\text { stability }\end{array}$ & & - & $\begin{array}{c}.102 \\
{[-.008,} \\
.215]\end{array}$ & $\begin{array}{l}.143 * * \\
{[.029,} \\
.254]\end{array}$ & $\begin{array}{c}.109 \\
{[-.017,} \\
.233]\end{array}$ & $\begin{array}{c}.011 \\
{[-.109,} \\
.126]\end{array}$ & $\begin{array}{c}-.037 \\
{[-.152,} \\
.076]\end{array}$ \\
\hline $\begin{array}{l}\text { 3. Sense of } \\
\text { competence }\end{array}$ & & & - & $\begin{array}{l}.376 * * \\
{[.267,} \\
.467]\end{array}$ & $\begin{array}{l}.195 * * \\
{[.079,} \\
.304]\end{array}$ & $\begin{array}{l}.265 * * \\
{[.143} \\
.372]\end{array}$ & $\begin{array}{l}.322 * * \\
{[.215,} \\
.425]\end{array}$ \\
\hline $\begin{array}{l}\text { 4. Interest in } \\
\text { learning }\end{array}$ & & & & - & $\begin{array}{l}.565^{\star *} \\
{[.477,} \\
.648]\end{array}$ & $\begin{array}{l}.647^{\star \star} \\
{[.571} \\
.719]\end{array}$ & $\begin{array}{l}.339 * * \\
{[.231,} \\
.437]\end{array}$ \\
\hline $\begin{array}{l}\text { 5. Utility value } \\
\text { of learning }\end{array}$ & & & & & - & $\begin{array}{l}.491^{\star *} \\
{[.401} \\
.575]\end{array}$ & $\begin{array}{l}.142 * \\
{[.022,} \\
.260]\end{array}$ \\
\hline $\begin{array}{l}\text { 6. Mastery goal } \\
\text { orientation }\end{array}$ & & & & & & - & $\begin{array}{l}.496 * * \\
{[.407,} \\
.573]\end{array}$ \\
\hline $\begin{array}{l}\text { 7. Performance } \\
\text { goal orientation }\end{array}$ & & & & & & & - \\
\hline
\end{tabular}

Note. $N=303 .{ }^{*} p<.05,{ }^{*} p<.01$

Table 2. Hierarchical Regression Analyses Assessing the Moderating Role of Emotional Stability and Gender in the Association between Extraversion and Adolescents' Performance Goal Orientation.

\begin{tabular}{|l|c|l|l|}
\hline Parameter & $B$ & \multicolumn{1}{|c|}{$S E$} & \multicolumn{1}{|c|}{$R^{2}$} \\
\hline Model 1 & & & -.004 \\
\hline Extraversion & $\begin{array}{c}.049 \\
{[-.071, .167]}\end{array}$ & .060 & \\
\hline Emotional stability & -.061 & .067 & \\
& {$[-.192, .071]$} & & \\
\hline Gender & $\begin{array}{c}.047 \\
{[-.163, .356]}\end{array}$ & .132 & \\
\hline Model 2 & & & .033 \\
\hline
\end{tabular}




\begin{tabular}{|l|c|l|l|}
\hline $\begin{array}{c}\text { Extraversion*Emotional } \\
\text { stability }\end{array}$ & $\begin{array}{c}.237 * * \\
{[.056, .275]}\end{array}$ & .056 & \\
\hline Model 3 & & & .035 \\
\hline Extraversion*Gender & $\begin{array}{c}.063 \\
{[-.155, .357]}\end{array}$ & .130 & \\
\hline Model 4 & & & .037 \\
\hline $\begin{array}{l}\text { Extraversion*Gender*Emotional } \\
\text { stability }\end{array}$ & $\begin{array}{c}.093 \\
{[-.168, .329]}\end{array}$ & .126 & \\
\hline
\end{tabular}

Note. $N=$ 303. $S E=$ Standard Error. $95 \%$ confidence intervals shown in brackets. Gender was coded as $0=$ girls, $1=$ boys. $* * p<.01$.

Table 3. Hierarchical Regression Analyses Assessing the Moderating Role of Sense of Competence and Gender in the Association between Emotional Stability and Adolescents' Interest in Learning.

\begin{tabular}{|c|c|c|c|}
\hline Parameter & $B$ & $S E$ & $R^{2}$ \\
\hline Model 1 & & & .159 \\
\hline Emotional stability & $\begin{array}{c}.153^{*} \\
{[.036, .269]} \\
\end{array}$ & .059 & \\
\hline Sense of competence & $\begin{array}{c}.355^{* *} \\
{[.255, .471]} \\
\end{array}$ & .055 & \\
\hline Gender & $\begin{array}{c}-.082 \\
{[-.410, .070]}\end{array}$ & .122 & \\
\hline Model 2 & & & .178 \\
\hline $\begin{array}{l}\text { Emotional } \\
\text { stability*Sense of } \\
\text { competence }\end{array}$ & $\begin{array}{c}.186^{* *} \\
{[.034, .249]}\end{array}$ & .055 & \\
\hline Model 3 & & & .179 \\
\hline $\begin{array}{l}\text { Emotional } \\
\text { stability*Gender }\end{array}$ & $\begin{array}{c}-.042 \\
{[-.311, .174]}\end{array}$ & .123 & \\
\hline Model 4 & & & .181 \\
\hline $\begin{array}{l}\text { Emotional } \\
\text { stability*Gender*Sense } \\
\text { of competence }\end{array}$ & $\begin{array}{c}-.094 \\
{[-.385, .132]}\end{array}$ & .132 & \\
\hline
\end{tabular}

Note. $N=303 . S E=$ Standard Error. $95 \%$ confidence intervals shown in brackets. Gender was coded as 0 = girls, 1 = boys. ${ }^{*} p<.05 ;{ }^{* *} p<.01$.

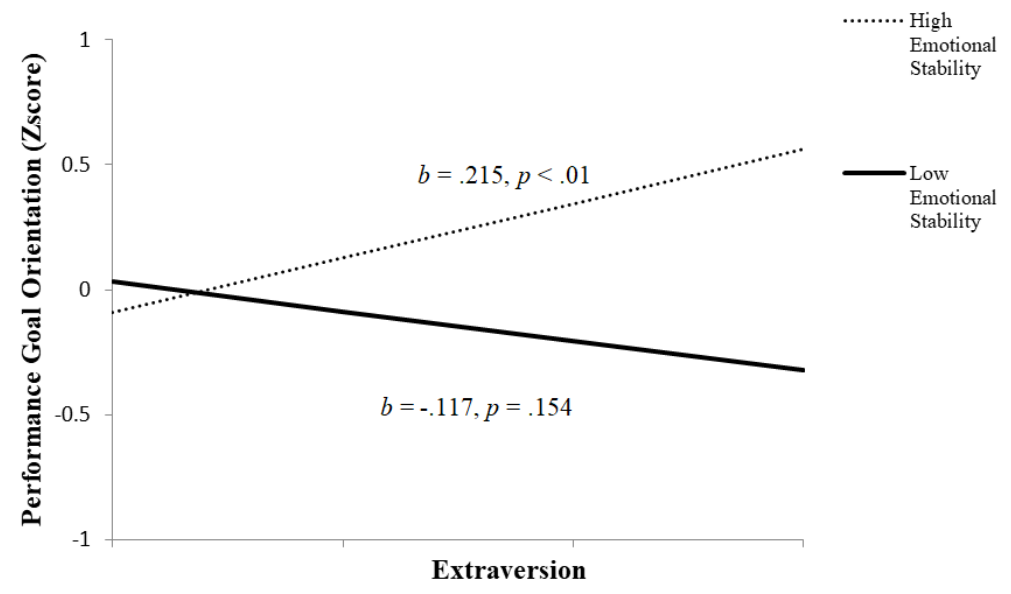

Figure 1. The Relationship between Extraversion and Performance Goal Orientation, as moderated by Emotional Stability. 


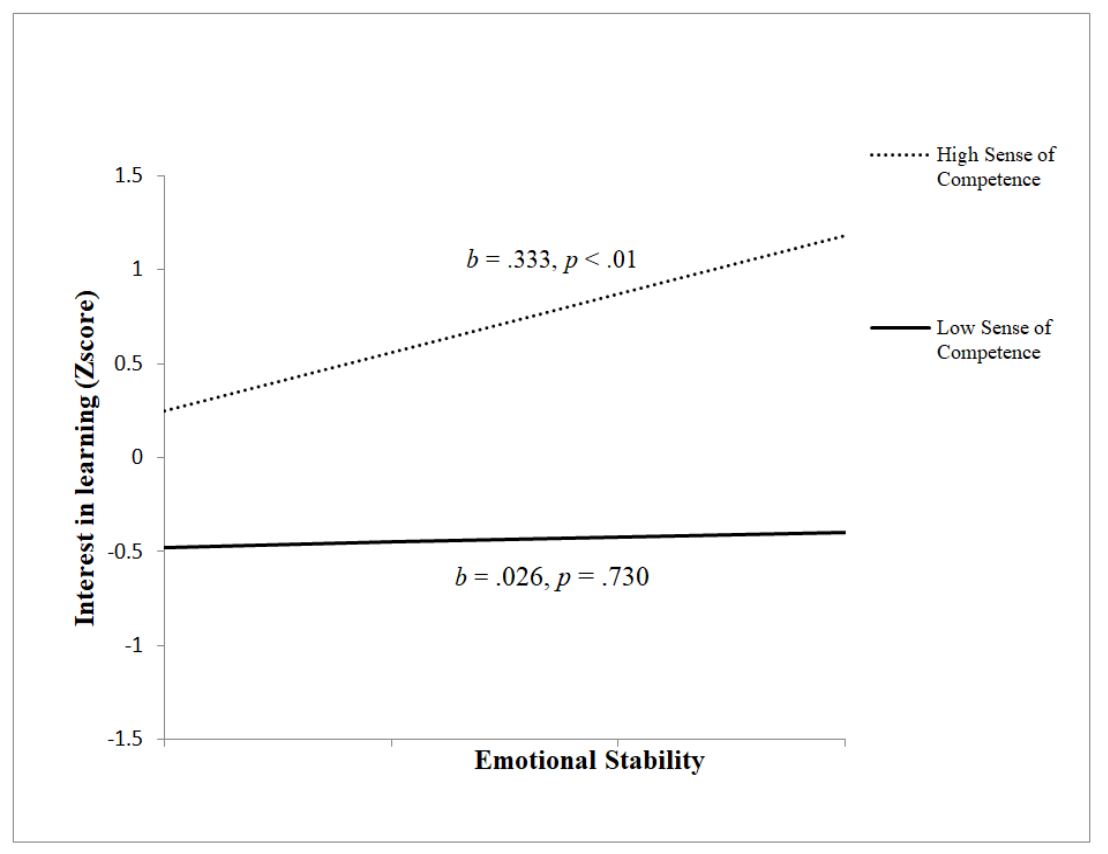

Figure 2. The Relationship between Emotional Stability and Interest in Learning, as moderated by Sense of Competence.

\section{Discussion}

The results presented above shed light on the interrelationships between the two personality traits of extraversion and emotional stability and the five motivational dimensions of sense of competence, interest, utility value, and mastery and performance goal orientations. These results are interpreted in light of the pre-existing data which, again, is very limited.

\section{Interdimensional correlations between personality traits and motivational dimensions}

First, an analysis of the interdimensional correlations turned up associations that are already well-documented, both between personality traits and between motivational dimensions. Indeed, results show a significant and positive association between the traits of emotional stability and extraversion, corroborating much research that has shown that individuals who display high levels of outgoingness and sociability also tend to display positive emotionality (Morris et al., 2015; Speed et al., 2018; Van der Linden et al., 2010). Our analysis also indicates significant positive associations between the motivational dimensions of sense of competence, interest, utility value, mastery goal orientation, and performance goal orientation. Once more, a great deal of research has shown that students' appraisal of the value of learning situations can be closely linked to their assessment of their ability to perform well in these situations (Gaspard et al., 2018; Kosovich et al., 2017; Smith et al., 2017). Moreover, another unsurprising link to emerge from our analysis is the association between emotional stability and gender. Specifically, boys were found to be more emotionally stable than girls. In many contexts, it has been observed that boys may show less emotional responsiveness than girls when exposed to the same experiences and situations (Costa et al., 2001; Ones \& Anderson, 2002). Perhaps the most interesting result emerging from this first analysis is the significant positive association between emotional stability and interest in learning. This result echoes a finding that was shared almost thirty years ago by Little, Lecci and Watkinson (1992), who found that emotionally unstable learners experienced less enjoyment in learning activities.

Influence of the personality traits on motivational dimensions revealing of value placed on learning

Our main analysis consisted of finer modelling. This analysis generated results that better capture the influence of extraversion and emotional stability personality traits on motivational dimensions that are revealing of value placed on learning.

These models show that extraversion interacts with emotional stability predicts the pursuit of performance goals. Specifically, students with extraverted tendencies appear more likely 
to pursue performance goals when they are also highly emotionally stable. The same extraverted students, when they have low emotional stability, do not seem to have the same inclination to want to perform well in a learning situation. This result again highlights the fact that people who are outgoing and sociable often tend to display positive emotionality (Morris et al., 2015; Speed et al., 2018; Van der Linden et al., 2010). But most importantly, it indicates that it is more this combination of traits-rather than any one of them taken in isolation-that helps determine the type of behaviors that students tend to adopt in learning situations. Specifically, both personality and motivational characteristics seem to concurrently influence students' inclination to demonstrate or secure social recognition for one's ability. Thus, as a few researchers have previously observed, it would seem that students who display positive emotionality are more enthusiastic (Little, Lecci and Watkinson, 1992) about learning, are more inclined to set learning-related goals (Watson and Hubbard, 1996) and tend to want to approach rather than avoid learning situations (Busato et al., 1999; Komarraju \& Karau, 2005). Of course, extraversion also seems to influence how students approach learning, but this association appears to be less strong and echoes contradictory results that have previously pointed to an ambiguous relation between extraversion and motivation to learn. Indeed, it has been observed that this trait can be favourable (Clark \& Schroth, 2010; Heaven, 1990; Kaufman et al., 2008; Little, Lecci, \& Watkinson (1992) or unfavourable (Clark \& Schroth, 2010; Kaufman et al., 2008; Komarraju et al., 2009; Komarraju \& Karau, 2005). In the latter case, it is possible that these students, who tend to be extraverted, are confronted with a "forced choice dilemma" (Smith et al., 2020) and ultimately choose to meet their need for social affiliation at the expense of their learning needs (Little, Lecci, \& Watkinson, 1992).

These models also show that emotional stability interacts with sense of competence and predicts interest in learning. Specifically, students with greater emotional stability appear to be more interested in learning when they also feel competent. This finding allows for a more refined interpretation of the relationship between sense of competence and interest in learning. As we have seen, it is well documented that students tend to value learning more when they feel they have the skills required to learn effectively (Gaspard et al., 2018; Kosovich et al., 2017; Smith et al., 2017). Our analyses show that positive emotionality combines with a strong sense of competence and leads to students welcoming new learning opportunities. This finding naturally mirrors Little, Lecci and Watkinson (1992), though their analyses only dealt with the relationship between emotional stability and enjoyment experienced in different kinds of situations. Given this finding, it is not surprising to observe that emotionally stable students show more interest in learning, just as those who are confident in their skills tend to show similarly high interest.

Taken together, these results suggest that differences in students' expectations of success, or in the value they place on learning, may in some way be related to personality traits such as extraversion and emotional stability. These findings should encourage teachers to consider how these traits impact their teaching methods, and how they can adapt the support they provide to their students and thus give them equal opportunities to acquire motivational resources that are conducive to their learning. Sensitivity to such characteristics could also facilitate teachers' classroom management, since students with high motivation tend to adopt better behaviors.

\section{Limitations}

This being said, these results should be interpreted prudently. One of the limitations of this study is its concurrent nature. The interpretation of the associations between personality traits and motivational dimensions is based on data collected at a single time point and we cannot assume the stability of these relationships over time. Regardless, it is worth recalling that these results corroborate previous findings and there is reason to believe that they are not merely attributable to special circumstances or chance.

Along these lines, it is possible that the associations we have found between personality and motivational characteristics in adolescents would not be replicated with younger or older learners. However prior research on older learners suggests that these associations do exist and may even last over time.

Some research also suggests that personality traits may be more prevalent in some cultures and communities, perhaps because of differences in values (Lavine, 2009; Marchand, 2004; Triandis, 2001). These values may be related to individual characteristics, and together, these values and characteristics could produce and explain various 
behavioural tendencies. Importantly, our sample is not representative of the cultural, ethnic, social and sexual diversity found in society and the results may be influenced by this fact.

Most importantly, it should not be overlooked that our analyses focused on two personality traits drawn from a model that contains five (McCrae \& Costa, 2003; the model also incorporates the traits of openness to experience, conscientiousness and agreeableness). However, the two traits in question are usually correlated, and more importantly, the findings of less precise analytical work (Smith et al., 2019) suggest that these traits could be more closely associated with the motivational dimensions considered in this study, which predict expectations of success and value placed on learning.

Finally, our sample size was relatively small and homogeneous, which limits the generalizability of our findings. Future research should try to replicate previous results using larger diverse samples.

\section{Future directions}

This study has led to novel observations, namely that personality and motivational characteristics interact with one another to influence student approaches to learning. This provides interesting avenues for future research, including the use of a longitudinal design to assess how personality traits and motivational dimensions' covary over time. In the event that a longitudinal design is chosen, it would be sound to include all of the Big 5 personality traits, since a new analytical undertaking of this type might generate results that could not emerge from cross-sectional analyses. Such a study may help identify hitherto unsuspected associations between personality traits and motivational dimensions and, consequently, provide a basis for better interpreting why students develop differing relationships with learning.

\section{Acknowledgement}

The authors would like to thank the Sherbrooke branch of the Interuniversity Centre for Research on Teacher Training and the Teaching Profession for providing financial support in the publication of this article

\section{References}

Adamek, L., Nichols, S., Tetenbaum, S. P., Bregman, J., Ponzio, C. A., \& Carr, E. G. (2011). Individual temperament and problem behavior in children with autism spectrum disorders. Focus on Autism and Other Developmental Disabilities, 26(3), 173-183. https://doi.org/10.1177/1088357611405041

Ambady, N., Shih, M., Kim, A., \& Pittinsky, T. L. (2001). Stereotype susceptibility in children: Effects of identity activation on quantitative performance. Psychological Science, 12(5), 385-390. https://doi.org/10.1111/14679280.00371

Atkinson, J. W. (1957). Motivational determinants of risk-taking behavior. Psychological Review, 64(6), 359372. https://doi.org/10.1037/h0043445

Bandura, A. (2012). On the functional properties of perceived self-efficacy revisited. Journal of management, 38(1), 9-44. https://doi.org/10.1177/0149206311410606

Bernard, L. C. (2014). Evolved individual differences in human motivation. In R. M. Ryan (Ed.), The Oxford handbook of human motivation (pp. 381-407). Oxford University Press. https://doi.org/10.1093/oxfordhb/9780195399820.001.0001

Bouffard, T., \& Vezeau, C. (2015). Intention d'apprendre, motivation et apprentissage autorégulé: Le role de la perception de compétence et des émotions. In M. Crahay \& M. Dutrévis (Eds.), Psychologie des apprentissages scolaires $\left(2^{\text {nd }}\right.$ ed., pp. 95-114). De Boeck.

Bouffard, T., Vezeau, C., Romano, G., Chouinard, R., Bordeleau, L., \& Filion, C. (1998). Élaboration et validation d'un instrument pour évaluer les buts des élèves en contexte scolaire. Revue canadienne des sciences du comportement, 30(3), 203-206.

Busato, V. V., Prins, F. J, Elshout, J. J., \& Hamaker, C. (1999). The relation between learning styles, the Big Five personality traits and achievement motivation in higher education. Personality and Individual Differences, 26(1), 129-140. https://doi.org/10.1016/S0191-8869(98)00112-3

Clark, M. H., \& Schroth, C. A. (2010). Examining relationships between academic motivation and personality among college students. Learning and Individual Differences, 20(1), 19-24. https://doi.org/10.1016/j.lindif.2009.10.002

Cohen, G. L., Steele, C. M., \& Ross, L. D. (1999). The mentor's dilemma: Providing critical feedback across the racial divide. Personality and Social Psychology Bulletin, 25(10), 1302-1318. 
https://doi.org/10.1177/0146167299258011

Costa, P. T., Jr, Terracciano, A., \& McCrae, R. R. (2001). Gender differences in personality traits across cultures: Robust and surprising findings. Journal of Personality and Social Psychology, 81(2), 322-331. https://doi.org/10.1037/0022-3514.81.2.322

Cuadrado, D., Salgado, J. F., \& Moscoso, S. (2020). Personality, intelligence, and counterproductive academic behaviors: A meta-analysis. Journal of Personality and Social Psychology. Advance online publication. https://doi.org/10.1037/pspp0000285

David, J. P., Green, P. J., Martin, R., \& Suls, J. (1997). Differential roles of neuroticism, extraversion, and event desirability for mood in daily life: An integrative model of top-down and bottom-up influences. Journal of Personality and Social Psychology, 73(1), 149-159. https://psycnet.apa.org/doi/10.1037/0022-3514.73.1.149

De Feyter, T., Caers, R., Vigna, C., \& Berings, D. (2012). Unraveling the impact of the Big five personality traits on academic performance: The moderating and mediating effects of self-efficacy and academic motivation. Learning and Individual Differences, 22(4), 439-448. https://doi.org/10.1016/j.lindif.2012.03.013

De Pauw, S. S. W., Mervielde, I., \& Van Leeuwen, K. G. (2009). How are traits related to problem behavior in preschoolers? Similarities and contrasts between temperament and personality. Journal of Abnormal Child Psychology, 37(3), 309-325. https://doi.org/10.1007/s10802-008-9290-0

DeYoung, C. G., Hirsh, J. B., Shane, M. S., Papademetris, X., Rajeevan, N., \& Gray, J. R. (2010). Testing predictions from personality neuroscience: Brain structure and the big five. Psychological science, 21(6), 820828. https://doi.org/10.1177/0956797610370159

Dotterer, A. M., McHale, S. M., \& Crouter, A. C. (2009). The development and correlates of academic interests from childhood through adolescence. Journal of Educational Psychology, 101(2), 509-519.

Eccles, J., Wigfield, A., Harold, R. D., \& Blumenfeld, P. (1993). Age and gender differences in children's selfand task perceptions during elementary school. Child Development, 64(3), 830-847. https://doi.org/10.1111/j.1467-8624.1993.tb02946.x

Eccles, J. S., \& Wigfield, A. (1995). In the mind of the actor: The structure of adolescents' achievement tasks values and expectancy-related beliefs. Personality and Social Psychology Bulletin, 21(3), 215-225. https://doi.org/10.1177\%2F0146167295213003

Eccles-Parsons, J., Adler, T. F., Futterman, R., Goff, S. B., Kaczala, C. M., \& Meece, J. L. (1983). Expectancies, values, and academic behavior. In J. T. Spence (Ed.), Achievement and achievement motives. Psychological and sociological approaches (pp. 75-146). W. H. Freeman.

Elliot, A. J., Murayama, K., \& Pekrun, R. (2011). A 3X2 achievement goal model. Journal of Educational Psychology, 103(3), 632-648. https://doi.org/10.1037/a0023952

Fredricks, J. A., \& Eccles, J. S. (2002). Children's competence and value beliefs from childhood to adolescence: Growth trajectories in two male-sex-typed domains. Developmental Psychology, 38(4), 519-533. https://doi.org/10.1037/0012-1649.38.4.519

Frenzel, A. C., Goetz, T., Pekrun, R., \& Watt, H. M. G. (2010). Development of mathematics interest in adolescence: Influences of gender, family, and school context. Journal of Research on Adolescence, 20(2), 507-537. https://doi.org/10.1111/j.1532-7795.2010.00645.x

Gaspard, H., Wigfield, A., Jiang, Y., Nagengast, B., Trautwein, U., \& Marsh, H. W. (2018). Dimensional comparisons: How academic track students' achievements are related to their expectancy and value beliefs across multiple domains. Contemporary Educational Psychology, 52, 1-14. https://doi.org/10.1016/j.cedpsych.2017.10.003

Gottfried, A. E., Marcoulides, G. A., Gottfried, A. W., \& Oliver, P. H. (2009). A latent curve model of parental motivational practices and developmental decline in math and science academic intrinsic motivation. Journal of Educational Psychology, 101(3), 729-739. https://doi.org/10.1037/a0015084

Grant, H., \& Dweck, C. S. (2003). Clarifying achievement goals and their impact. Journal of Personality and Social Psychology, 85(3), 541-553. https://doi.org/10.1037/0022-3514.85.3.541

Heaven, P. C. L. (1990). Attitudinal and personality correlates of achievement motivation among high school students. Personality and Individual Differences, 11(7), 705-710. https://doi.org/10.1016/0191-8869(90)90255$\mathrm{P}$

Hofstede, G., \& McCrae, R. R. (2004). Personality and culture revisited: Linking traits and dimensions of culture. Cross-Cultural Research, 38(1), 52-88. https://doi.org/10.1177/1069397103259443

Holmbeck, G. N. (2002). Post-hoc probing of significant moderational and mediational effects in studies of pediatric populations. Journal of Pediatric Psychology, 27(1), 87-96. https://doi.org/10.1093/jpepsy/27.1.87

Kaufman, J. C., Agars, M. D., \& Lopez-Wagner, M. C. (2008). The role of personality and motivation in predicting early college academic success in non-traditional students at a Hispanic-serving institution. Learning and Individual Differences, 18(4), 492-496. https://doi.org/10.1016/j.lindif.2007.11.004

Komarraju, M., \& Karau, S. J. (2005). The relationship between the Big Five personality traits and academic 
motivation. Personality and Individual Differences, 39(3), 557-567. https://doi.org/10.1016/j.paid.2005.02.013

Komarraju, M., Karau, S. J., \& Schmeck, R. R. (2009). Role of the big five personality traits in predicting college students' academic motivation and achievement. Learning and Individual Differences, 19(1), 47-52. https://doi.org/10.1016/j.lindif.2008.07.001

Kosovich, J. J., Flake, J. K., \& Hulleman, C. S. (2017). Short-term motivation trajectories: A parallel process model of expectancy-value. Contemporary Educational Psychology, 49, 130-139.

https://doi.org/10.1016/j.cedpsych.2017.01.004

Kulig, T. C., Cullen, F. T., Wilcox, P., \& Chouhy, C. (2019). Personality and adolescent school-based victimization: Do the Big Five matter? Journal of School Violence, 18(2), 176-199. https://doi.org/10.1080/15388220.2018.1444495

Lavine, R. A. (2009). Personality traits across cultures and research on obedience. American Psychologist, 64(7), 620. https://doi.org/10.1037/a0017285

Little, B. R., Lecci, L., \& Watkinson, B. (1992). Personality and personal projects: Linking big five and PAC units of analysis. Journal of Personality, 60(2), 501-525. https://doi.org/10.1111/j.1467-6494.1992.tb00982.x

Lu, L., Shih, J. B., Lin, Y. Y., \& Ju, L. S. (1997). Personal and environmental correlates of happiness. Personality and Individual Differences, 23(3), 453-462. https://doi.org/10.1016/S0191-8869(97)80011-6

Lucas, R. E., \& Fujita, F. (2000). Factors influencing the relation between extraversion and pleasant affect. Journal of personality and social psychology, 79(6), 1039-1056. https://doi.org/10.1037/00223514.79.6.1039

Machimbarrena, J. M., Álvarez-Bardón, A., León-Mejía, A., Gutiérrez-Ortega, M., Casadiego-Cabrales, A., \& González-Cabrera, J. (2019). Loneliness and Personality Profiles Involved in Bullying Victimization and Aggressive Behavior. School Mental Health, 11(4), 807-818. https://doi.org/10.1007/s12310-019-09328-y

Martin, A. J. (2009). Age appropriateness and motivation, engagement, and performance in high school: Effects of age within cohort, grade retention, and delayed school entry. Journal of Educational Psychology, 101(1), 101-114. http://dx.doi.org/10.1037/a0013100

Matthews, G., \& Zeidner, M. (2004). Traits, states, and trilogy of mind: An adaptative perspective on intellectual functioning. In D. Y. Dai \& R. J. Sternberg (Eds.), Motivation, emotion, and cognition: Integrative perspectives on intellectual functioning and development (pp. 143-174). Erlbaum.

McAdams, D. P., \& Pals, J. L. (2007). The role of theory in personality research. In R. W. Robins, R. C. Fraley, \& R. F. Krueger (Eds.), Handbook of research methods in personality psychology (pp. 3-20). The Guilford Press.

McCrae, R. R., \& Costa, P. T. (2003). Personality in adulthood: A five-factor theory perspective (2nd ed.). The Guilford Press.

McCrae, R. R., \& Costa, P. T. (2006). Perspectives de la théorie des cinq facteurs (TCF): traits et culture. Psychologie française, 51(3), 227-244. https://doi.org/10.1016/j.psfr.2005.09.001

McCrae, R. R., Costa, P. T., Jr., Ostendorf, F., Angleitner, A., Hřebíčková, M., Avia, M. D., . . Smith, P. B. (2000). Nature over nurture: Temperament, personality, and life span development. Journal of Personality and Social Psychology, 78(1), 173-186. https://doi.org/10.1037/0022-3514.78.1.173

McKown, C., \& Weinstein, R. S. (2008). Teacher expectations, classroom context, and the achievement gap. Journal of School Psychology, 46(3), 235-261. https://doi.org/10.1016/j.jsp.2007.05.001

Mervielde, I., De Clercq, B., De Fruyt, F., \& Van Leeuwen, K. (2005). Temperament, personality, and developmental psychopathology as childhood antecedents of personality disorders. Journal of Personality Disorders, 19(2), 171-201. https://doi.org/10.1521/pedi.19.2.171.62627

Morizot, J. (2014). Construct validity of adolescents' self-reported big five personality traits: Importance of conceptual breadth and initial validation of a short measure. Assessment, 21(5), 580-606. https://doi.org/10.1177\%2F1073191114524015

Morizot, J., \& Miranda, D. (2007). Approche des traits de personnalité: Postulats, controverses et progrès récents. Revue de psychoéducation, 36(2), 363-416.

Morris, M. B., Burns, G. N., Periard, D. A., \& Shoda, E. A. (2015). Extraversion-emotional stability circumplex traits and subjective well-being. Journal of Happiness Studies, 16(6), 1509-1523. https://doi.org/10.1007/s10902-014-9573-9

Murray McNiel, J., \& Fleeson, W. (2006). The causal effects of extraversion on positive affect and neuroticism on negative affect: Manipulating state extraversion and state neuroticism in an experimental approach. Journal of Research in Personality, 40, 529-550. https://doi.org/10.1016/j.jrp.2005.05.003

Nolen, S. B., \& Ward, C. J. (2008). Sociocultural and situative approaches to studying motivation. In M. Maehr, S. Karabenick, \& T Urdan (Eds), Social psychological perspective on motivation and achievement. Advances in motivation and achievement (vol. 15, pp. 425-460). Emerald Group.

Norem, J. K., \& Cantor, N. (1986). Defensive pessimism: Harness anxiety as motivation. Journal of Personality 
and Social Psychology, 51(6), 1208-1217. https://doi.org/10.1037/0022-3514.51.6.1208

Ntamakiliro, L., Monnard, I., \& Gurtner, J. L. (2000). Mesure de la motivation scolaire des adolescents : construction et validation de trois échelles comportementales. L'Orientation Scolaire et Professionnelle, 29(4), 673-693. https://doi.org/10.4000/osp.5788

Ones, D. S., \& Anderson, N. (2002). Gender and ethic group differences on personality scales in selection: Some British data. Journal of Occupational \& Organizational Psychology, 75(3), 255-276. https://doi.org/10.1348/096317902320369703

Pekrun, R. (1993). Facets of adolescents' academic motivation: A longitudinal expectancy-value approach. In M. L. Maehr et P. R. Pintrich (Eds.), Advances in motivation and achievement: Motivation in adolescence (vol. 8, pp. 139-189). JAI Press.

Phillips, P., Abraham, C., \& Bond, R. (2003). Personality, cognition, and university students' examination performance. European Journal of Personality, 17(6), 435-448. https://doi.org/10.1002/per.488

Pintrich, P. R., \& Schrauben, B. (1992). Students' motivational beliefs and their cognitive engagement in classroom academic tasks. In D. H. Shunk \& J. L. Meece (Eds.), Student perceptions in the classroom (pp. 149-183). Erlbaum.

Pinxten, M., Marsh, H. W., De Fraine, B., Van Den Noortgate, W., \& Van Damme, J. (2014). Enjoying mathematics or feeling competent in mathematics? Reciprocal effects on mathematics achievement and perceived math effort expenditure. British Journal of Educational Psychology, 84(1), 152-174. https://doi.org/10.1111/bjep.12028

Putwain, D. W., Larkin, D., \& Sander, P. (2013). A reciprocal model of achievement goals and learning related emotions in the first year of undergraduate study. Contemporary Educational Psychology, 38(4), 361-374. https://doi.org/10.1016/j.cedpsych.2013.07.003

Renninger, K. A., \& Hidi. S. (2011). Revisiting the conceptualization, measurement, and generation of interest. Educational Psychologist, 46(3), 168-184. https://doi.org/10.1080/00461520.2011.587723

Rheinberg, F., Vollmeyer, R., \& Rollett, W. (2000). Motivation and action in self-regulated learning. In M. Boekaerts, P. R. Pintrich, \& M. Zeidner (Eds.), Handbook of self-regulation (pp. 503-529). Academic Press.

Schermerhorn, A. C., Bates, J. E., Goodnight, J. A., Lansford, J. E., Dodge, K. A., \& Pettit, G. S. (2013). Temperament moderates associations between exposure to stress and children's externalizing problems. Child development, 84(5),1579-1593. https://doi.org/10.1111/cdev.12076

Schunk, D. H., \& DiBenedetto, M. K. (2020). Motivation and social cognitive theory. Contemporary Educational Psychology, 60, 101832. https://doi.org/10.1016/j.cedpsych.2019.101832

Séguin, D. G., \& MacDonald, B. (2018). The role of emotion regulation and temperament in the prediction of the quality of social relationships in early childhood. Early Child Development and Care, 188(8), 1147-1163. https://doi.org/10.1080/03004430.2016.1251678

Smith, J., Chouinard, R., Bergeron, J., \& St-Amand, J. (2017). The motivation of students facing failure who experienced an alternative to grade repetition. Nouveaux cahiers de la recherche en éducation, 20(2), 122140. https://doi.org/10.7202/1053591ar

Smith, J., Grégoire, P., \& Paquin, S. (2019, May 23-26). Examination of the role of the introversionextraversion personality trait in motivation to learn [Poster presentation], Association for Psychological Science, Washington DC, United States.

Smith, J., Moreau, D., Paquin, S., St-Amand, J., \& Chouinard, R. (2020). The evolution of motivation to learn in the context of the transition to secondary school: Developmental trajectories and relational determinants. The International Journal of Pedagogy and Curriculum, 27(2), 17-37. https://doi.org/10.18848/23277963/CGP/v27i02/17-37

Speed, B. C., Nelson, B. D., Levinson, A. R., Perlman, G., Klein, D. N., Kotov, R., \& Hajcak, G. (2018). Extraversion, neuroticism, and the electrocortical response to monetary rewards in adolescent girls. Biological psychology, 136, 111-118. https://doi.org/10.1016/j.biopsycho.2018.05.017

Triandis, H. C. 2001. Individualism-collectivism and personality. Journal of Personality, 69(6), 907-924. https://doi.org/10.1111/1467-6494.696169

Usher, E. L., \& Pajares, F. (2008). Self-efficacy for self-regulated learning: A validation study. Educational and Psychological Measurement, 68(3), 443-463. https://doi.org/10.1177/0013164407308475

Van der Linden, D., Scholte, R. H., Cillessen, A. H., te Nijenhuis, J., \& Segers, E. (2010). Classroom ratings of likeability and popularity are related to the Big Five and the general factor of personality. Journal of Research in Personality, 44(5), 669-672. https://doi.org/10.1016/j.jrp.2010.08.007

Vreeke, L. J., \& Muris, P. (2012). Relations between behavioral inhibition, big five personality factors, and anxiety disorder symptoms in non-clinical and clinically anxious children. Child Psychiatry \& Human Development, 43(6), 884-894. https://doi.org/10.1007/s10578-012-0302-5

Watson, D., \& Hubbard, B. (1996). Adaptational style and dispositional structure: Coping in the context of the five-factor model. Journal of Personality, 64(4), 737-774. https://doi.org/10.1111/j.1467-6494.1996.tb00943.x 
Wigfield, A., Tonks, S., \& Klauda, S. L. (2016). Expectancy-value theory. In K. R. Wentzel, \& D. B. Miele (Eds.). Handbook of motivation at school ( $2^{\text {nd }}$ ed., pp. 55-74). Routledge. https://doi.org/10.4324/9781315773384

Yeager, D. S., Purdie-Vaughns, V., Garcia, J., Apfel, N., Brzustoski, P., Master, A., ... Cohen, G. L. (2014). Breaking the cycle of mistrust: Wise interventions to provide critical feedback across the racial divide. Journal of Experimental Psychology: General, 143(2), 804-824. https://doi.org/10.1037/a0033906 